\title{
Using Maximum Power Capability of Fuel Cell in Direct Methanol Fuel Cell / Battery Hybrid Power System
}

\author{
Mehdi Dargahi (Corresponding author) \\ Islamic Azad University - Jouybar Branch \\ Jouybar, Iran \\ Tel: 98-911-128-7365Ｅ-mail: Dargahi.mehdi@gmail.com \\ Mohammad Rezanezhad \\ Faculty of Electrical Engineering, Babol University of technology \\ Shariati St. Babol, Iran \\ Tel: 98-911-314-2090Ｅ-mail: mrezanejad@stu.nit.ac.ir
}

\begin{abstract}
Considering limited ability of Direct Methanol Fuel cell (DMFC) systems to produce power and importance of optimum methanol consumption, it is necessary to provide conditions, in which, the maximum power of DMFC from present fuel flow can be utilized. But, in different conditions, maximum power point (MPP) of DMFC is a unique point. So, operating point should be determined based on DMFC conditions, and load requirements are not taken into account. This means that, output voltage will not be fixed if load resistance varies. In this paper, a new control scheme for DMFC/Battery hybrid power system is proposed and analyzed. In the proposed system, a MPP tracking controller searches for MPP of DMFC in any operating conditions. Moreover, a battery charge controller is utilized to keep the battery voltage in its permissible limits. So, in the proposed scheme, MPP operation of DMFC and output voltage regulation can be achieved concurrently.
\end{abstract}

Keywords: Direct Methanol Fuel cell, Battery, Maximum Power Point Tracking

\section{Introduction}

DMFC is one of the newest electric power sources, which become increasingly more attractive subject for many researchers because:

- A solid polymer electrolyte is used in these kinds of fuel cells (FCs),

- Their operational temperature is relatively low, and

- Their fuel is low cost and has high energy density (Jeong et al, 2008).

A large number of internal parameters can impact on produced voltage of DMFC (Jeong et al, 2008; Guo et al, 2004; Sundmacher et al, 2001), but in any condition, there is just one unique point on V-I curve which represents MPP. In this point, DMFC can produce its maximum power. Because of the limited ability of DMFC systems to produce power from available fuel flow, it is necessary to force the system to operate in condition which matches to DMFC's MPP. This can avoid excessive fuel consumption and low efficiency operation.

A Maximum power point tracking (MPPT) controller traces the MPP of DMFC using a MPPT algorithm. The controller generates instructions for a DC-DC converter and a certain amount of current which corresponds to MPP, is extracted from DMFC.

There are several methods to search extremum value of a function (Zhi-dan et al, 2008; Wasynczuck, 1983; Hussein etal, 1995; Noguchi et al, 2002; Enslin et al.1997). Among them Perturbation and Observe (P\&O) (Zhi-dan et al, 2008; Wasynczuck, 1983) is the most commonly used method because of its simple algorithm.

In this paper, DMFC MPPT, its problems and deficiencies, and proposed solution which is a hybrid Direct Methanol 
Fuel cell/Battery system is presented and analyzed.

In section II, DMFC power system is reviewed. In section III, the MPPT strategy is analyzed. In next section, section IV, the proposed hybrid system and its control scheme is introduced. The results and conclusion are presented in sections $\mathrm{V}$ and VI respectively.

\section{DMFC power system}

Such as other kinds of DMFC, there are three different regions in V-I curve of DMFC. At low current densities, the voltage is dominated by the electrochemical kinetics of the anodic methanol oxidation. As current density increases, the voltage decreases further due to limitations of methanol mass transport to the anode catalyst layer and the electric resistance of the membrane. In next region, the system approaches a limiting current density ilim at which the voltage decreases rapidly. The level of the limiting current density mainly depends on the mass transport resistance of methanol in the anode diffusion layer. Methanol mass transport is based on diffusive and convective transport mechanisms. In addition, depending on the operating conditions, it is influenced by the release of $\mathrm{CO} 2$ bubbles from the anode surface (Sundmacher; 2001).

A multi-step reaction mechanism is used to describe reactions inside a DMFC (Sundmacher; 2001), which can be summarized as:

Anode: $\mathrm{CH}_{3} \mathrm{OH}(\mathrm{l})+\mathrm{H}_{2} \mathrm{O}(\mathrm{l}) \stackrel{\mathrm{Pt} / \mathrm{Ru}}{\longrightarrow} \mathrm{CO}_{2}(\mathrm{~g})+6 \mathrm{H}^{+}+6 e^{-}$

Cathode : $\frac{3}{2} \mathrm{O}_{2}(\mathrm{~g})+6 \mathrm{H}^{+}+6 e^{-} \stackrel{P t}{\longrightarrow} 3 \mathrm{H}_{2} \mathrm{O}(\mathrm{l})$

Overall: $\mathrm{CH}_{3} \mathrm{OH}(\mathrm{l})+\frac{3}{2} \mathrm{O}_{2}(\mathrm{~g}) \longrightarrow \mathrm{CO}_{2}(\mathrm{~g})+2 \mathrm{H}_{2} \mathrm{O}(\mathrm{l})$

Output voltage of a DMFC is function of open circuit voltage, $U_{\text {cell }}^{S T D}$, anode overpotential, $\eta_{a}$, cathode overpotential, $\eta_{c}$ and membrane ohmic overpotential, $\eta_{\text {ohmic }}$.

$V_{\text {cell }}=U_{\text {cell }}^{S T D}-\eta_{a}+\eta_{c}-\eta_{\text {ohmic }}$

Using charge balance at anode and cathode sides following expressions can be achieved.

$$
\begin{aligned}
& \frac{d \eta_{a}}{d t}=\frac{1}{C_{a}}\left(i_{c e l l}-6 F r_{a}\right) \\
& \frac{d \eta_{c}}{d t}=\frac{1}{C_{c}}\left(-i_{c e l l}-6 F\left(r c+n_{M e O H}^{M}\right)\right)
\end{aligned}
$$

where, $\mathrm{F}$ is Faraday's constant, $\mathrm{C}_{\mathrm{a}}$ and $\mathrm{C}_{\mathrm{c}}$ are double layer capacities of anode and cathode respectively and $n_{M e O H}^{M}$ is mass flux density of methanol in membrane. Rate of methanol oxidation reaction at anode catalyst layer, $r_{a}$, and oxygen reduction at cathode catalyst layer, $\mathrm{r}_{\mathrm{c}}$, can be expressed as:

$$
\begin{aligned}
& r_{a}=k_{a}\left(x_{M e O H}^{C L} \exp \left(\frac{\alpha_{a} F}{R T} \eta_{a}\right)-x_{C O_{2}}^{C L} \exp \left(-\frac{\left(1-\alpha_{a}\right) F}{R T} \eta_{a}\right)\right) \\
& r_{c}=k_{c}\left(\left(\frac{P_{O_{2}}}{P^{S T D}}\right)^{1.5} \exp \left(-\frac{\alpha_{c} F}{R T} \eta_{c}\right)-\exp \left(\frac{\left(1-\alpha_{c}\right) F}{R T} \eta_{c}\right)\right)
\end{aligned}
$$

where, $\mathrm{k}_{\mathrm{c}}$ and $\mathrm{ka}$ are rate constant of anodic and cathodic reactions respectively, $x_{\mathrm{MeOH}}^{C L}$ and $x_{\mathrm{CO}_{2}}^{C L}$ are mole fraction of methanol and carbon dioxide, $\alpha_{a}$ and $\alpha_{c}$ are charge transfer coefficients, $P_{O_{2}}$ and $P^{S T D}$ are oxygen and standard pressures, $\mathrm{R}$ is universal gas constant, and $\mathrm{T}$ is temperature.

Extended studies about abovementioned relations and expressions can be found in (Jeong, 2008; Guo,2004; Sundmacher et al, 2001).

The output voltage of the fuel cell stack can be calculated by the following expression.

Vstack $=$ NVcell

where $\mathrm{N}$ is the number of single cells in stack. The output power of the stack is:

Pstack $=$ Vstack I

Choosing parameter values from (1), (2) and (3) the DMFC stack output voltage and power curves are presented in Figure1. 


\section{Maximum power point tracking strategy}

There are various methods to find extremum value of a function (which have mostly been developed for photovoltaic arrays), such as Perturbation and Observe (P\&O) (Zhi-dan et al, 2008; Wasynczuck, 1983 ), Incremental Conductance (Hussein etal, 1995), short-circuit current method (Noguchi et al, 2002), and the open-circuit voltage method (Enslin et al.1997 Enslin et al.1997). Considering its simple algorithm, P\&O is the most commonly used method.

In $\mathrm{P} \& \mathrm{O}$, as can be understood from its name, a perturbation is applied to system and its effect is observed. For DMFC system, an increment (either positive or negative) in DMFC current, $\Delta \mathrm{I}$, is considered as perturbation and output power variations, $\Delta \mathrm{P}$, will be observed. If output power is increased by a positive constant increment in DMFC current, further positive increment is needed; otherwise perturbation should be negative. In a similar way, if output power is decreased by a positive perturbation, further positive increment is needed; otherwise direction of perturbation variation should be changed. This algorithm can be summarized as flowchart shown in figure 2 .

For fast tracking of maximum power point, the perturbation range should be large. This leads to more fluctuations in output power. If we want to reduce these fluctuations, the perturbation range should be small, but tracking time will be long. So, as a summary, the quick tracking time is in conflict with the suppression of fluctuations in output power. Many approaches have been proposed to improve the $\mathrm{P} \& \mathrm{O}$ algorithm, such as using a variable step size of perturbation instead of a constant value as following (Huynh et al, 1996):

$I_{k+1}=I_{k}+M \frac{\Delta P_{k}}{\Delta I_{k}}$

where $\mathrm{M}$ is a coefficient that modifies step size, and $\mathrm{I}_{\mathrm{k}}, \Delta \mathrm{I}$ and $\Delta \mathrm{P}$ are the current value, deviation of current and deviation of power at $\mathrm{k}_{\mathrm{th}}$ sampling period respectively.

It should be noted that, in spite of appropriate behavior of $\mathrm{P} \& \mathrm{O}$ under static conditions, it will not function well if it encounters dynamic behavior of system (Zhi-dan et al, 2008). To obviate this drawback, continuous changes in DMFC operation should be avoided.

\section{Hybrid system and its control scheme}

A DC-DC power converter between DMFC and load can change load equivalent resistance seen by DMFC. At MPP, current gain of the converter, G, has a value which causes the load equivalent resistance to be equal to the internal resistance of the DMFC. The relationship between load equivalent resistance $\mathrm{R}_{\mathrm{eq}}$ and load resistance $\mathrm{R}_{\text {Load }}$ is:

$\mathrm{R}_{\text {eq }}=\mathrm{G}^{2} \mathrm{R}_{\mathrm{Load}}$

A MPPT controller uses DMFC voltage, current and subsequently its power, to find MPP and then generates control instructions for the power converter. The converter forces the fuel cell to work at current which is defined by MPPT controller and corresponds to MPP of DMFC. In this point, the load equivalent resistance is equal to the internal resistance of the DMFC and maximum power can be delivered to load, considering maximum power transfer principle. Figure 3 shows a generic schematic diagram of such a system.

As an example of MPPT for a DMFC system, Figure 4 shows a plot of the DMFC stack power in standard conditions. As can be seen, the MPP is found by MPPT controller and DMFC is forced to stay at this operating point.

In order to operate in MPP, DMFC output current should be constant; so, load can just receive a fixed current and power. Consequently, changes in load resistance will result in variations in output voltage. Figure 5 shows the operation of system under variable load resistance condition.

To overcome the described deficiencies, a DMFC/Battery hybrid system, which represented in Figure 6, is proposed.

In this system, battery is placed in parallel with the power converter, and is responsible to keep the output voltage constant. In order to keep the battery voltage in a predetermined limit, a battery charge controller is employed. The controller Input is the battery voltage, and its output determines the DMFC input fuel flow. This controller works in the way that, for example, if we want to keep output voltage in $100 \pm 5 \%$ of nominal voltage, when battery voltage increases to its upper limit, i.e. $100+5 \%$, fuel flow will decrease to its minimum value, i.e. $0 \%$. On the contrary, when battery voltage rises to its lower limit, i.e. 100-5\%, battery charge controller decreases the fuel flow up to its maximum, i.e. $100 \%$. So, with respect to load requirements, battery voltage and subsequently, DMFC input fuel flow, change in the way that, load demand is satisfied and output bus voltage is kept constant. MPPT controller traces the MPP of DMFC, in any fuel flow conditions, and sends the required instructions to the DC-DC converter, so that MPP operation of DMFC can be realized.

In order to avoid rapid and sudden changes of fuel flow, which can have serious and harmful damages for DMFC, a low pass filter should be utilized in battery charge controller output. The filter only passes slow and soft changes of fuel flow to the DMFC. To have an appropriate understanding for designing of this filter, maximum allowed rate of variations of fuel flow, which can be tolerated by DMFC, should be taken into account. Then, the filter can be tuned to 
realize the desired settings. Figure 7 shows the response of a typical low pass filter with a damping factor of 1 , for different cut-off frequencies, when a step change is applied as its input. Choosing such a damping factor will avoid any oscillations.

\section{Simulation and results}

Parameters and relationships presented in section II are used to model a DMFC stack.

A $220 \mathrm{~V}$ lead-acid battery is used in this study. These kinds of batteries are employed in many electrical systems to store or deliver energy. There have been many proposals for lead-acid battery models. A comprehensive electrical circuit model for lead-acid batteries was proposed in (Salameh et al, 1992). This model can be simplified to the circuit shown in figure 8 (Wang and Nehrir, 2007). In this circuit model, $\mathrm{Cb}$ is battery capacitance, Rs is self-discharge resistance, Ri is internal resistance, Co is overvoltage capacitance, and Ro is overvoltage resistance. The battery is considered fully charged before the application of load, and permissible range for voltage is considered $100 \pm 5 \%$ of nominal voltage.

For power electronics intermediates, Buck-Boost DC-DC converters are employed. State-space averaged model can be used to analyze the converters performance (Rashid, 2001). These models can represent the average behavior of converters in steady state as well as in transients.

In order to analyze the performance of the proposed configuration, the system is tested in two stages. First, MPPT controller is tested separately, and results are shown. In the next stage, the fuel flow which determined by battery charge controller is applied to DMFC, and effects of load resistance changes on system performance are analyzed.

To investigate performance of the MPPT controller, hypothetical step changes are applied to input fuel flow of DMFC. Considering such changes, DMFC output power vs. its current is depicted in figure 9.a. Figure 9.b shows the output power of DMFC which is extracted by DC-DC converter based on MPPT controller instructions.

As can be seen, MPP of DMFC for different values of input fuel flow is traced continuously and operation of DMFC becomes fixed in this point.

Now, by adding the battery charge controller to system, the effects of load resistance changes on system performance will be analyzed. In this condition, the controller changes the input fuel flow of DMFC continuously. The filter cut-off frequency is set to $1 \mathrm{~Hz}$ and the damping factor is 1 . Step changes of load resistance are shown in figure 10.a. The calculated fuel flow and DMFC output power are presented in figure 10.b and figure 10.c respectively. Figure 10.d represents the voltage of battery terminals.

As can be seen in above figures, in spite of the fact that changes of load resistance is in a wide range, it has no effect on the MPPT controller performance, and MPP is traced continuously. Moreover, battery voltage is regulated in the determined limits, satisfactorily.

\section{Conclusion}

Considering the importance of high efficiency operation and optimum fuel consumption in DMFC power systems, it is necessary to provide conditions in which DMFC can operate in its MPP, but as described in this paper, there are some problems. In order to overcome these deficiencies, a new configuration for Fuel cell / Battery hybrid power system is proposed and analyzed. This system is able to utilize DMFC maximum power and regulate output voltage simultaneously, using two sets of controller. One is a DC-DC converter in addition to a MPPT controller, which uses $\mathrm{P} \& \mathrm{O}$ algorithm to trace MPP. The next is a battery charge controller which regulates battery voltage by changing the input fuel flow of DMFC. So, both MPP operation of DMFC and output voltage regulation can be realized.

The proposed system is simulated and results demonstrate appropriate performance of the system and controllers.

\section{References}

Enslin, J., Wolf, M.S., Snyman, D.B. and Swiegers, W., (1997). "Integrated Photovoltaic Maximum Power Point Tracking Converter. IEEE Trans. on Industrial Electronics, vol. 44, pp. 769-773.

Guo, H., Ma, C., (2004). 2D analytical model of a direct methanol fuel cell. Electrochemistry Communications 6, pp. 306-312.

Hussein, K., Muta, I. Hoshino, T. and Osakada, M. (1995). Maximum Photovoltaic Power Tracking: An Algorithm for Rapidly Changing Atmospheric Conditions. IEE Proc.-Generation, Transmission, Distribution, Vol. 142, No.1, pp. 59-64.

Huynh, P., Cho, B.H., (1996). Design and Analysis of a Microprocessor-Controlled Peak-Power-Tracking System. IEEE Trans. Aerosp. Electron. Syst. 32 (1), pp. 182-190.

Jeong, I., Kim, J., Pak, S., Nam, S., Moon, I., (2008). Optimum operating strategies for liquid-fed direct methanol fuel cells. Journal of Power Sources 185, pp. 828-837.

M. H. Rashid, (2001). Power Electronics Handbook, New York: Academic. 
Noguchi, T., Togashi, S., Nakamoto, R., (2002). Short-Current Pulse-Based Maximum-Power-Point Tracking Method for Multiple Photovoltaic and Converter Module System. IEEE Trans. on Industrial Electronics, vol. 49, pp. $217-223$.

Salameh, Z. M., Casacca, M. A., and Lynch, W. A., (1992). A mathematical model for lead-acid batteries. IEEE Trans. Energy Convers., vol. 7, no. 1, pp. 93-98.

Sundmacher, K., Schultz, T., Zhou, S., Scott, K., Ginkel, M., Gilles, E.D. (2001). Dynamics of the direct methanol fuel cell (DMFC): experiments and model-based analysis. Chemical Engineering Science 56, pp. 333-341.

Wang, C., Nehrir, H., (2007). Load Transient Mitigation for Stand-Alone Fuel Cell Power Generation Systems. IEEE Trans. Energy Conversion, 22(4), pp. 864-872.

Wasynczuck, O., (1983). Dynamic Behavior of a Class of Photovoltaic Power Systems. IEEE Trans. Apparatus and Systems, Vol. PAS-102, No. 9, pp. 3031-3037.

Zhi-dan, Z., Hai-bo, H., Xin-jian, H., Guang-yi, C., Yuan, R., (2008). Adaptive maximum power point tracking control of fuel cell power plants. J. Power Sources 176, pp. 259-269.

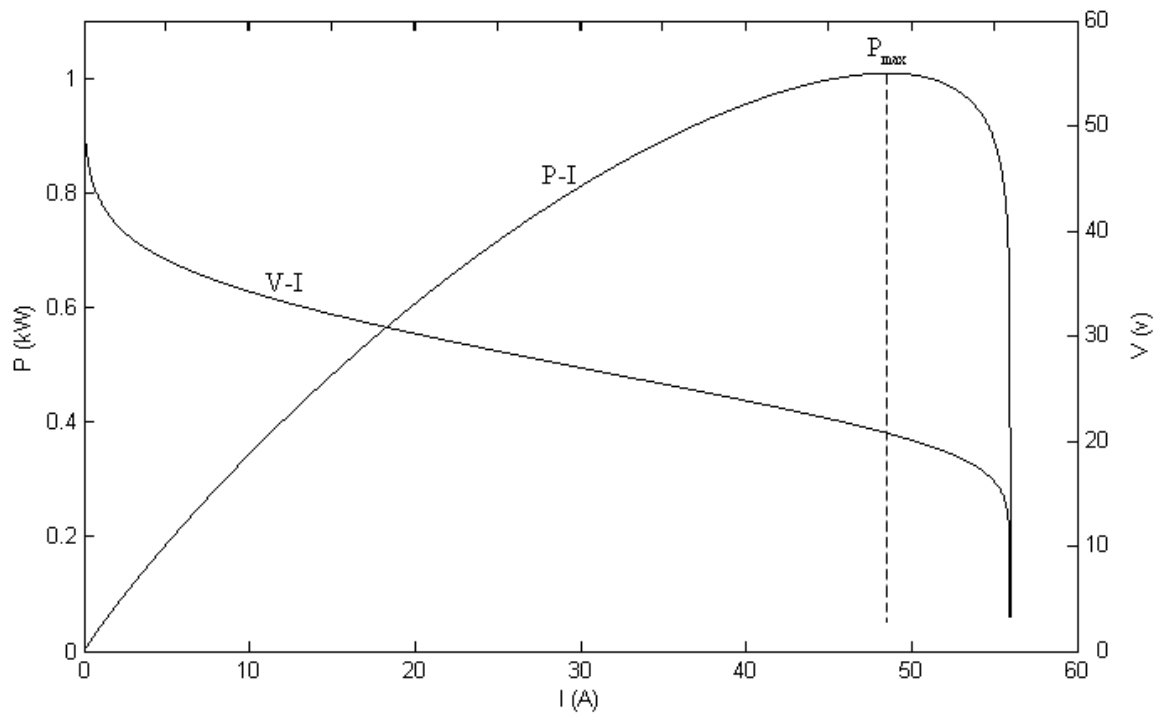

Figure 1. DMFC stack output voltage and power v.s. its current curves

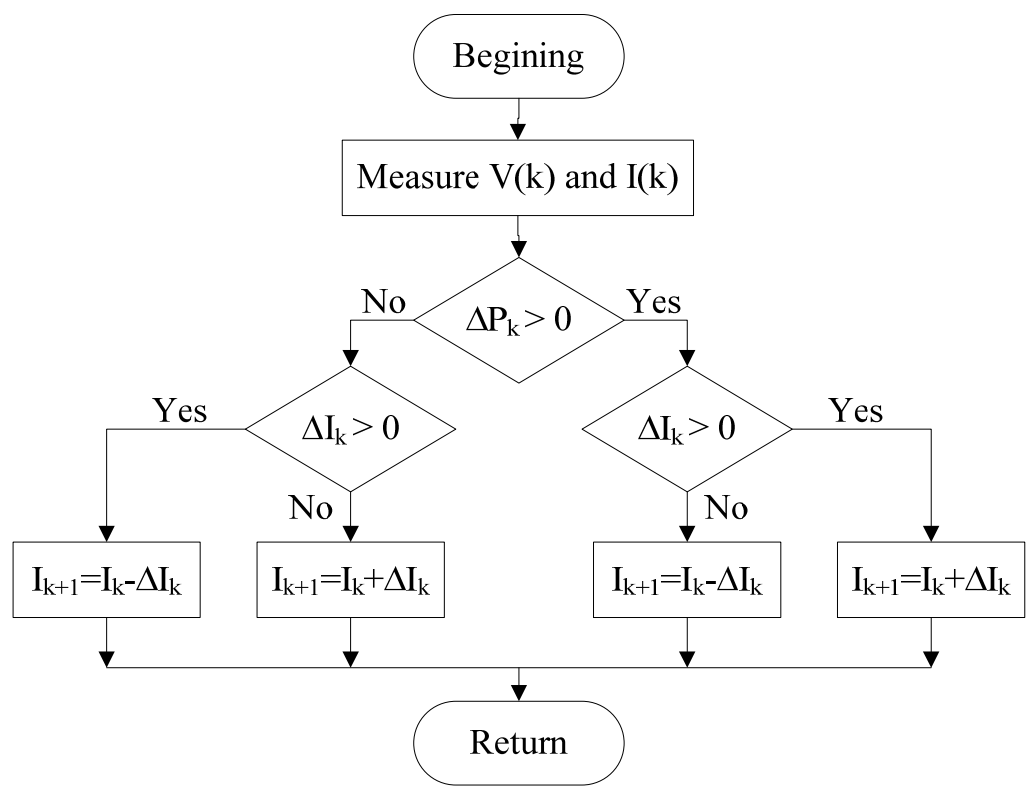

Figure 2. Flowchart of $\mathrm{P} \& \mathrm{O}$ algorithm 


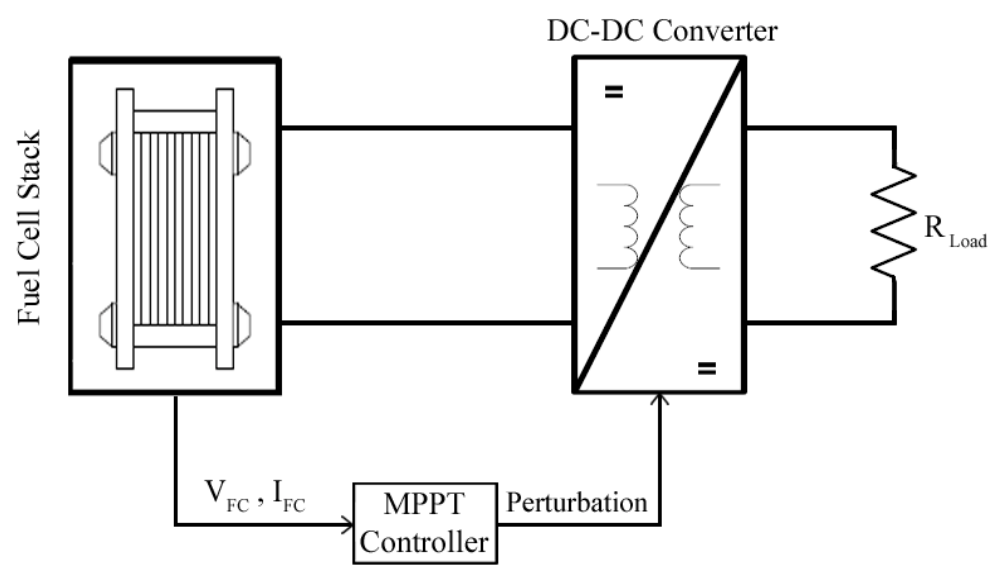

Figure 3. Schematic diagram of MPPT fot DMFC system

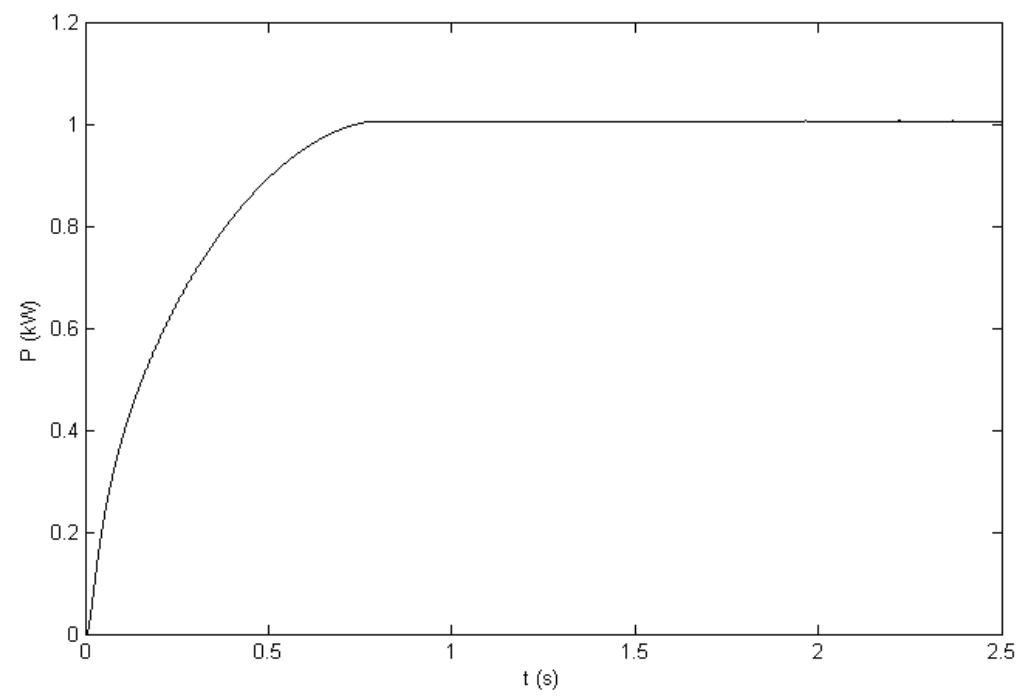

Figure 4. MPPT for a DMFC system in standard conditions 


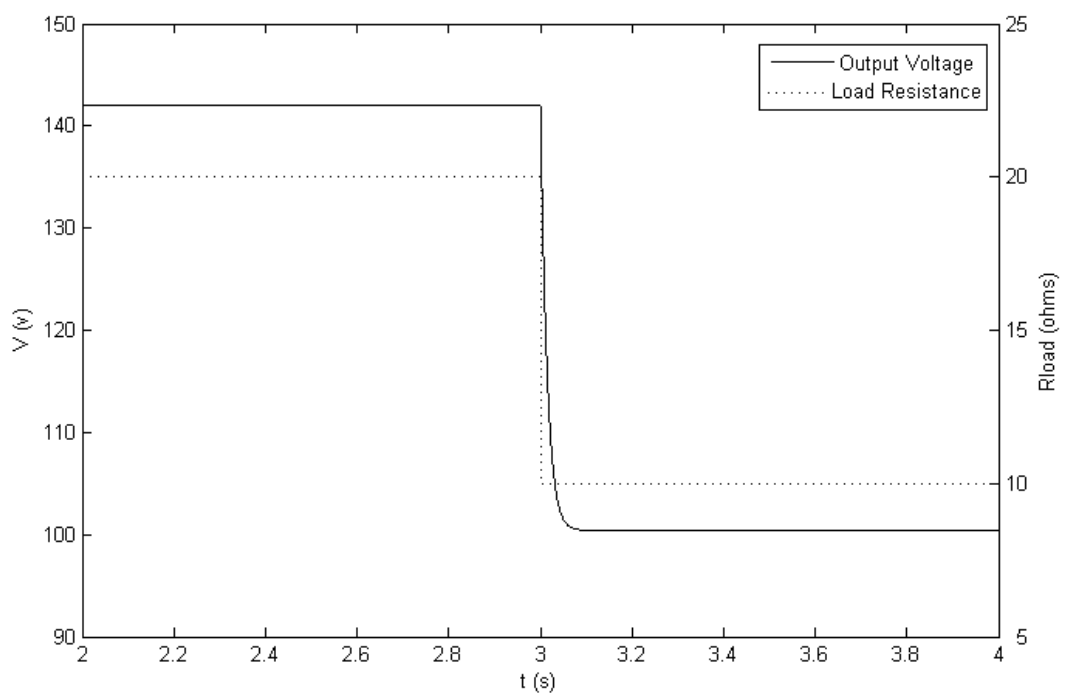

Figure 5. Output voltage variations when load resistance varies

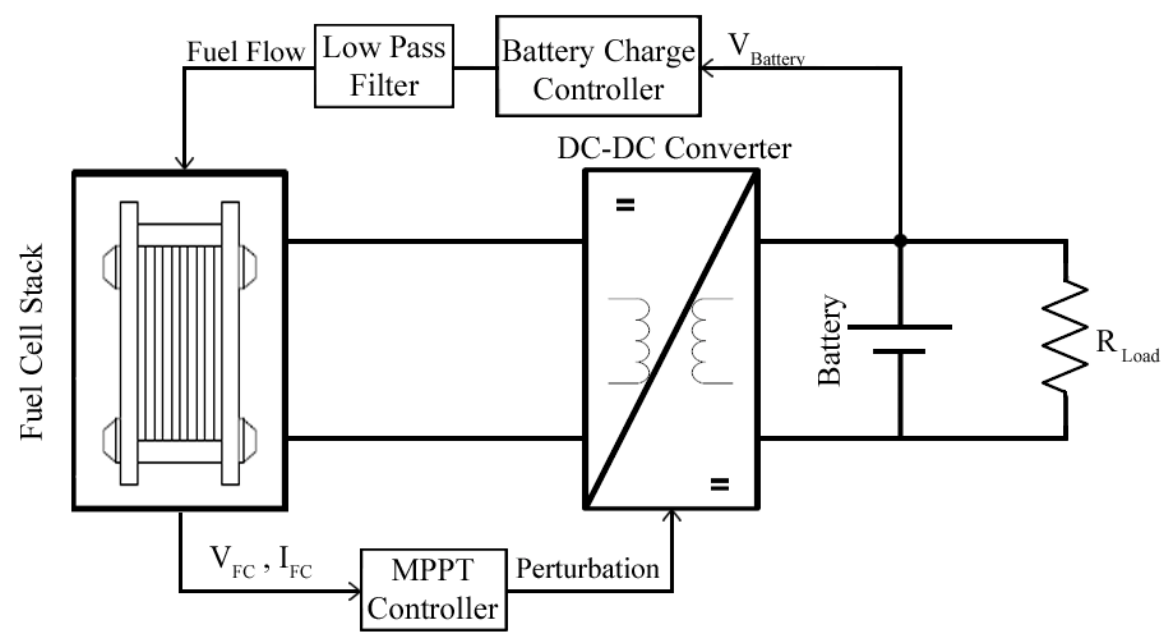

Figure 6. Complete proposed DMFC/Battery hybrid system 


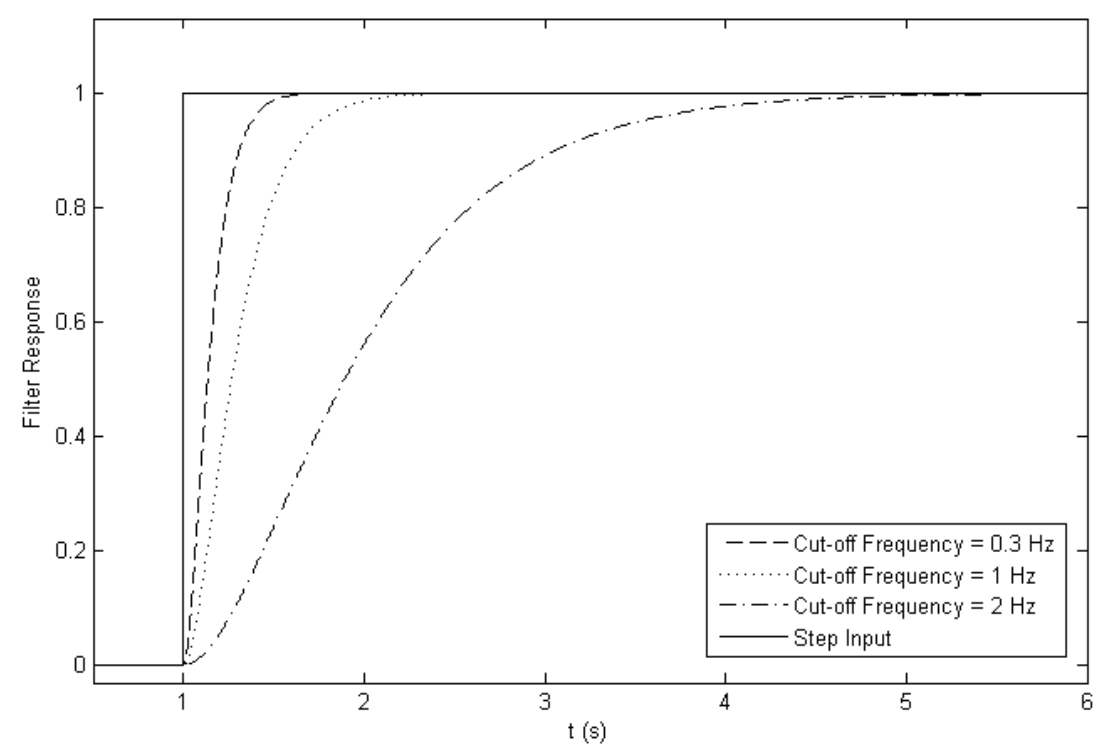

Figure 7. Response of a typical low pass filter to step input for different values of cut-off frequency

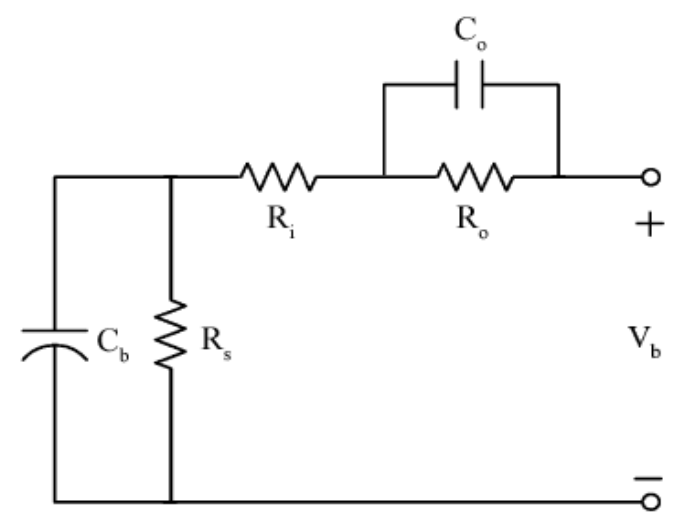

Figure 8. Simplified model for lead-acid batteries 


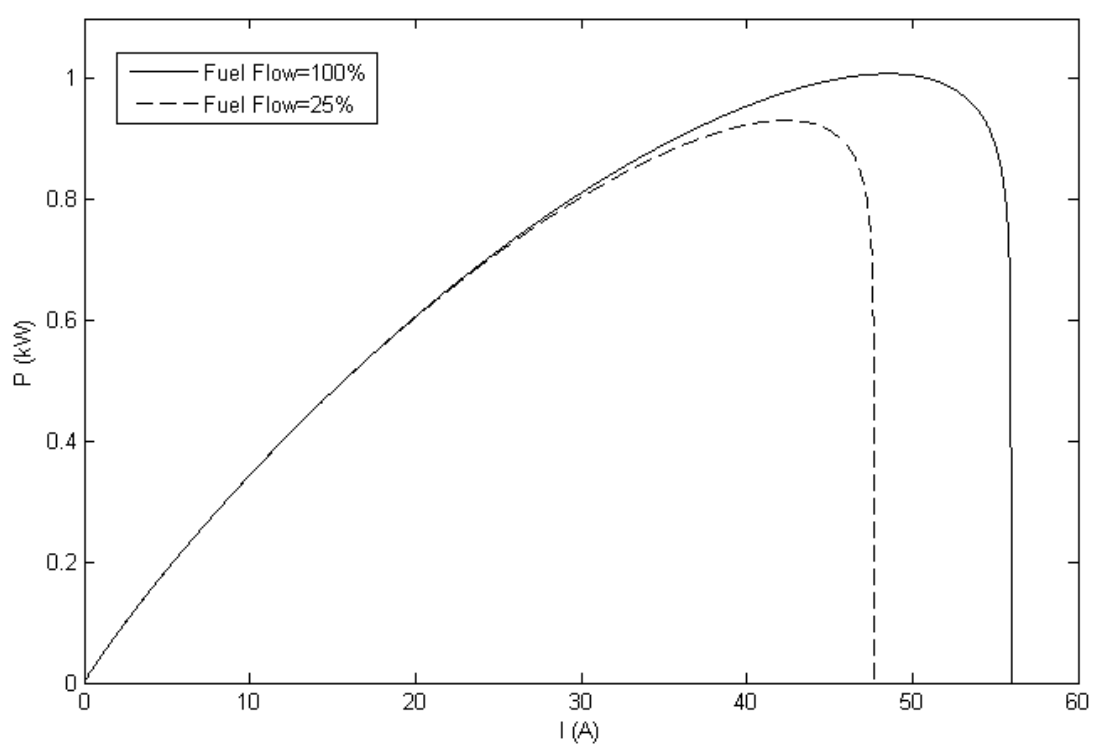

(a)

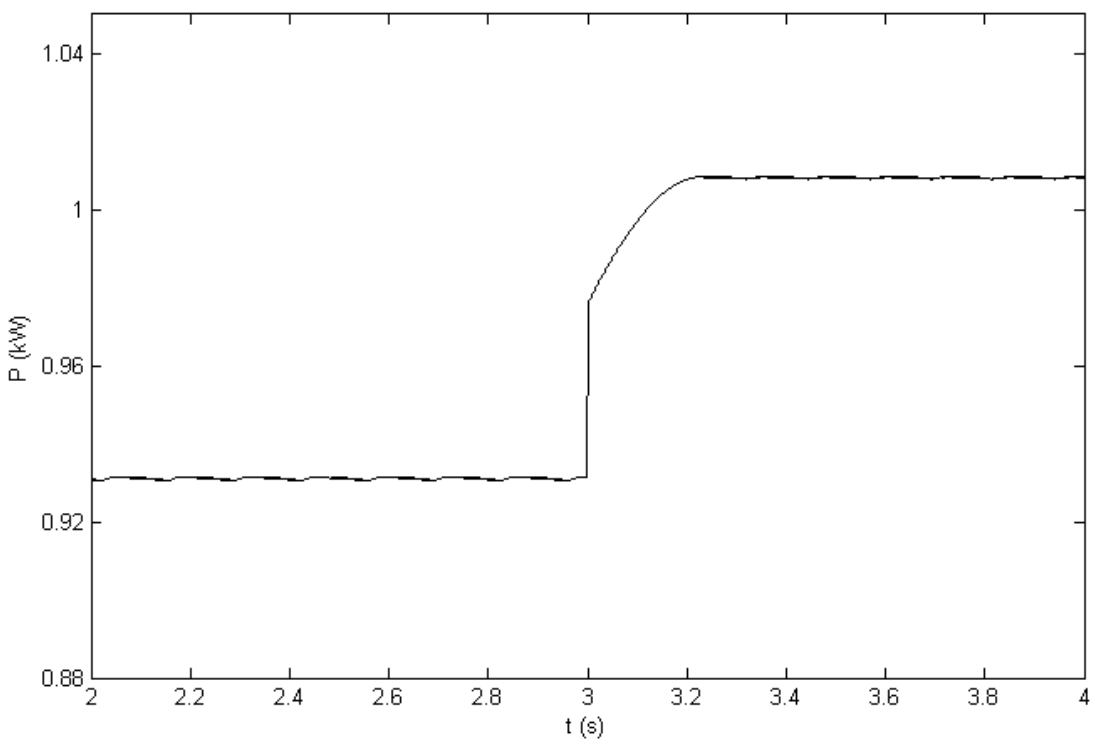

(b)

Figure 9. system performance when step changes are applied to input fuel flow.

a) DMFC output power vs. its current, b) output power of DMFC 


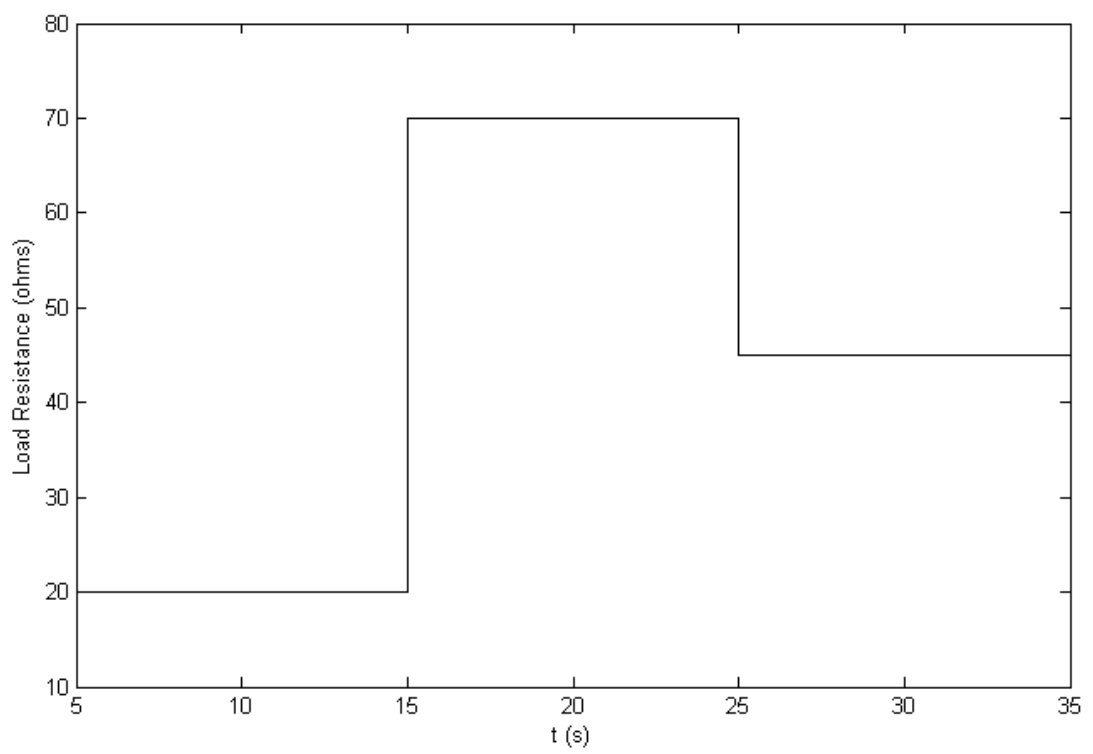

(a)

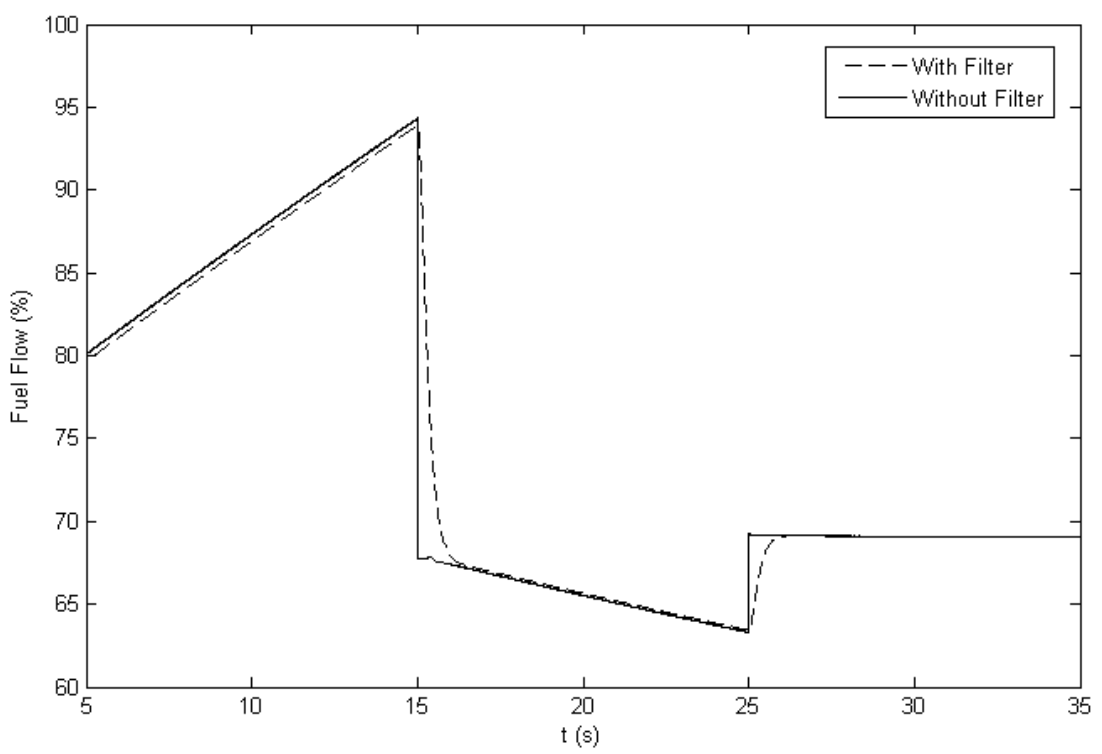

(b) 


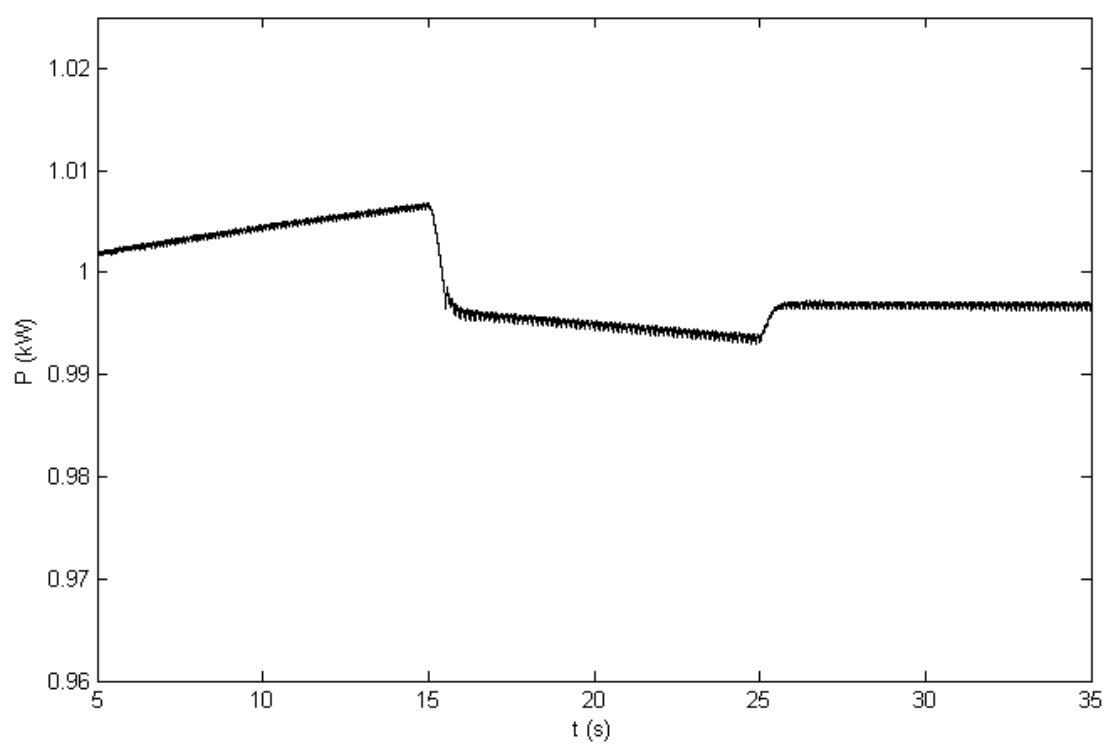

(c)

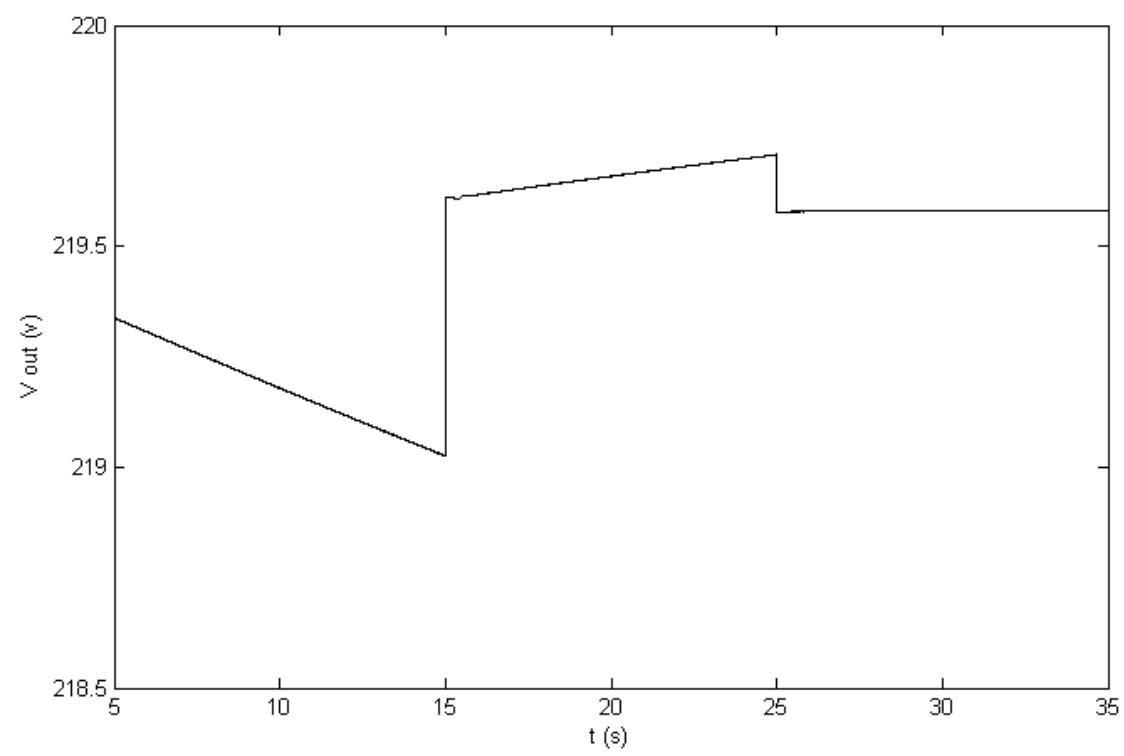

(d)

Figure 10. System performance under variable load resistance condition,

a) Step changes applied to load resistance, b) Variations of DMFC input fuel flow, c) FC output power, d) Battery voltage 